\title{
Staphylococcus cohnii subsp. urealyticus
}

National Cancer Institute

\section{Source}

National Cancer Institute. Staphylococcus cohnii subsp. urealyticus. NCI Thesaurus. Code C124404.

A subspecies of Staphylococcus cohnii that is positive for urease, beta-glucuronidase, and beta-galactosidase activities, with delayed alkaline phosphatase activity and the ability to produce acid aerobically from alpha-lactose. This subspecies is most frequently isolated in homes and is only rarely encountered in the hospital setting. 